\title{
General Comparison of Seismic Design between the Chinese Code and the European code
}

\author{
Ding Zhiquan ${ }^{1}$, Wang Zhizhao ${ }^{1}$ and $\mathrm{Li} \mathrm{Bo}^{1}$ \\ ${ }^{1}$ CCCC-FHDI Engineering Co., LTD, Guangzhou 510230, China
}

\begin{abstract}
To promote overseas projects, it is necessary for designers to understand and distinguish the similarities and differences between the Chinese standard GB50011(Edition 2016) and the European standard EN1998. By referring to relevant papers, comparing the ground types, response spectrum, structural importance factors, seismic precaution level and seismic zoning between the GB50011(Edition 2016) and EN1998, it can be concluded that the overall seismic design concepts in the Chinese and European codes are similar but there are some small differences in ground type classification, impact of ground type on seismic action, response spectrum, importance factor, seismic precautionary criterion, seismic precautionary measures, and seismic zone.
\end{abstract}

\section{Introduction}

GB50011-2010 (Edition 2016) Code for Seismic Design of Buildings [1] (hereinafter referred as "GB50011 Edition 2016") implemented since August 1, 2016, including provision modification on one appendix and 10 articles compared with the 2010 edition. On the other hand, European standard seismic design code EN1998, is divided into six parts from EN 1998-1 to EN1998-6. Among those, EN 1998-1 applies to the design of buildings and civil engineering works in seismic regions[2]; EN 1998-2 contains the particular requirements and rules applicable to the design of earthquake resistant bridges[3]; EN 1998-3 provides criteria for the evaluation of seismic performance and the design of retrofitting of existing building[4]; EN 1998-4 specifies the design of silos, tanks and pipelines [5]; EN 1998-5 provides design principle and rules for foundation, retaining structure and geotechnical aspects under seismic actions[6] and EN 1998-6 settles requirements, criteria and rules for the design of towers, masts, and chimneys [7].

Comparison studies between GB50011 and EN1998 have been made by some scholars such as: The Comparison of seismic design code of buildings between China and Europe (SONG, 2014, [8]), Comparison of Chinese codes and Europe codes about Seismic Design Provisions (HU, 2005, [9]), Comparative study of seismic design codes of China and Europe(CHEN et al, 2013, [10]) etc.. However, their studies are not introduced according to the design sequence and there are some revisions in GB50011 Edition 2016.

Besides, with the proposal and promotion of "One Belt and Road Initiatives", Chinese engineering companies are participating in a growing number of international projects and the domestic designers are inevitably facing the challenge of understanding of the international design standards. Increasing attention is paid to the seismic resistance standard which is very important for structural design.

Thus, in order to make clear and comprehensive understanding of the two codes' difference as per the design sequence, this article will be focusing on comparison between the GB50011 Edition 2016 and EN1998 regarding to contents including and not limited to site category division, response spectrum, structure importance factor, seismic categories and criterion, and the division of seismic zones. It will greatly improve the designer's understanding of similarities and differences between the two codes and provide reference for the designer who will do projects as per EN1998.

\section{Comparison in ground types classifi- cation}

\subsection{Ground types}

EN 1998 classifies the ground type according to the average shear wave velocity Vs,30 (or the standard penetration test blow-count number NSPT and the undrained shear strength of soil $\mathrm{Cu}$ if the average shear wave velocity is not available) into 7 categories as follows:

* Corresponding author: dingzq@fhdigz.com 
Table1. Ground types in EN1998-1

\begin{tabular}{|c|c|c|c|c|}
\hline \multirow{2}{*}{$\begin{array}{l}\text { Ground } \\
\text { type }\end{array}$} & \multirow[t]{2}{*}{ Description of stratigraphic profile } & \multicolumn{3}{|l|}{ Parameters } \\
\hline & & $v_{\mathrm{s}, 30}(\mathrm{~m} / \mathrm{s})$ & $\begin{array}{l}N_{\mathrm{SPT}} \\
\text { (olows } 30 \mathrm{~cm} \text { ) }\end{array}$ & $c_{\mathrm{u}}(\mathrm{kPa})$ \\
\hline A & $\begin{array}{l}\text { Rock or other rock-like geological } \\
\text { formation, including at most } 5 \mathrm{~m} \text { of } \\
\text { weaker material at the surface. }\end{array}$ & $>800$ & - & - \\
\hline B & $\begin{array}{l}\text { Deposits of very dense sand, gravel, or } \\
\text { very stiff clay, at least several tens of } \\
\text { metres in thickness, characterised by a } \\
\text { gradual increase of mechanical } \\
\text { properties with depth. }\end{array}$ & $360-800$ & $>50$ & $>250$ \\
\hline $\mathrm{C}$ & $\begin{array}{l}\text { Deep deposits of dense or medium- } \\
\text { dense sand, gravel or stiff clay with } \\
\text { thickness from several tens to many } \\
\text { hundreds of metres. }\end{array}$ & $180-360$ & $15-50$ & $70-250$ \\
\hline D & $\begin{array}{l}\text { Deposits of loose-to-medium } \\
\text { cohesionless soil (with or without some } \\
\text { soft cohesive layers), or of } \\
\text { predominantly soft-to-firm cohesive } \\
\text { soil. }\end{array}$ & $<180$ & $<15$ & $<70$ \\
\hline E & $\begin{array}{l}\text { A soil profile consisting of a surface } \\
\text { alluvium layer with } v_{5} \text { values of type } C \\
\text { or D and thickness varying between } \\
\text { about } 5 \mathrm{~m} \text { and } 20 \mathrm{~m} \text {, underlain by } \\
\text { stiffer material with } v_{\mathrm{s}}>800 \mathrm{~m} / \mathrm{s} \text {. }\end{array}$ & & & \\
\hline$S_{1}$ & $\begin{array}{l}\text { Deposits consisting, or containing a } \\
\text { layer at least } 10 \mathrm{~m} \text { thick, of soft } \\
\text { clays/silts with a high plasticity index } \\
(\mathrm{PI}>40) \text { and high water content }\end{array}$ & $\begin{array}{l}<100 \\
\text { (indicative) }\end{array}$ & - & $10-20$ \\
\hline$S_{2}$ & $\begin{array}{l}\text { Deposits of liquefiable soils, of } \\
\text { sensitive clays, or any other soil profile } \\
\text { not included in types A -E or } S_{1}\end{array}$ & & & \\
\hline
\end{tabular}

Specific studies for ground type $S_{1}$ or $S_{2}$ in determining the ground type is compulsory, and possibility of soil failure under seismic action shall also be considered particularly for $\mathrm{S}_{2}$. The analysis depth for the average shear wave velocity is $30 \mathrm{~m}$ in the EN1998.

On the other hand, the GB50011 Edition 2016 has taken both the average shear wave velocity and the thickness of soil layer covering the site into account when defining the ground types. The analysis depth for the average shear wave velocity is taken at the depth less than 20m. The GB50011 Edition 2016 has defined the ground types into 5 categories as follows:

Table2. Ground types in GB50011

\begin{tabular}{c|c|c|c|c|c}
\hline Average shear wave velocity (Vs)m/s & \multicolumn{5}{|c}{ Ground Types } \\
\hline & $\mathrm{I}_{0}$ & $\mathrm{I}_{0}$ & II & III & IV \\
\hline $\mathrm{v}_{\mathrm{s}} \geq 800$ & 0 & & & & \\
\hline $800 \mathrm{v}_{\mathrm{s}}>500$ & & 0 & & & \\
\hline $500 \geq \mathrm{v}_{\mathrm{se}}>250$ & & $<5$ & $\geq 5$ & & \\
\hline $250 \geq \mathrm{ve}_{\mathrm{se}}>150$ & & $<3$ & $3 \sim 50$ & $>50$ & \\
\hline $\mathrm{v}_{\mathrm{se}} \leqq 150$ & & $<3$ & $3 \sim 15$ & $15 \sim 80$ & $>80$
\end{tabular}

The major difference between the GB50011 Edition 2016 and EN1998 is that the GB 50011 has taken account of both average shear wave velocity and embedment thickness in the definition of ground types, while the EN1998 defines the ground type by a single factor of average shear wave velocity and does not consider the impact of soil 30m underneath; The EN 1998 has considered a deeper analysis depth for the average shear wave velocity and it's dividing the ground types into more detailed categories than that in GB50011 Edition 2016 .

\subsection{The impact of different ground types in designing seismic actions}

The ground types defined in GB50011 Edition 2016 is the only factor contributing to the value of characteristic period for response spectrum and does not contribute to the seismic intensity, hence the value of the seismic influence coefficient is consistent for different ground types, except when designing the medium-long period response spectrums. On the contrary, seismic intensity and characteristic period defined in the EN1998 are controlled by the type of ground. The approximate trend as suggested in EN1998 is that values of effective peak ground acceleration and characteristic period increases as the ground hardness decreases.

\section{Comparison in response spectrum}

Both standards adopt the response spectrum to describe the action of seismic. The GB50011 Edition 2016 introduces the seismic influence factor in modifying the response spectrum as in Figure 1, while the EN1998 introduces acceleration in the design of elastic response spectrum and with the introduction of behaviour factor q, the EN1998 is able to convert the elastic response spectrum into design response spectrum as in Figure 2 .

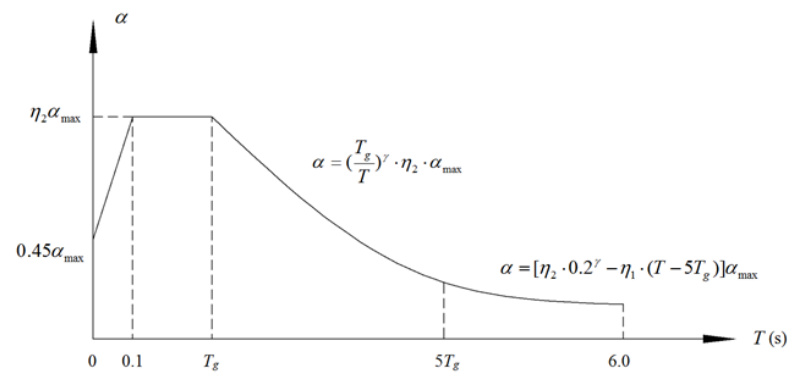

where:

$\alpha_{\max }$ :maximum value for seismic influence coefficient;

$\eta_{1}$ :modification factor for slope;

$\gamma:$ attenuation index;

$T_{g}:$ characteristic period;

$\eta_{2}$ :damping factor;

$T$ : natural period of structure vibration

Figure 1. Seismic response spectrum in GB50011 Edition

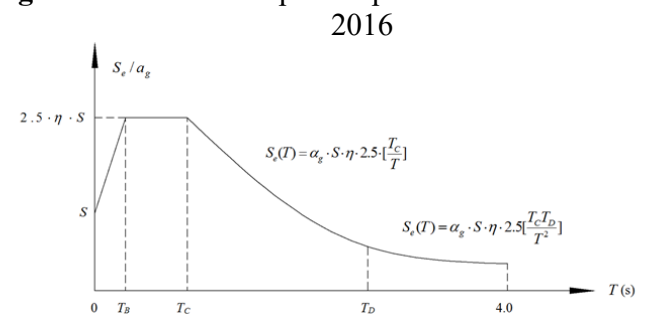

where:

$S_{s}(T)$ :elastic response spectrum;

$T$ : the vibration period a linear single-degree-of-freedom system;

$T_{B}$ : the lower limit of the period of the constant spectral acceleration branch;

$T_{C}$ : the upper limit of the period of the constant spectral acceleration branch;

$T_{D}$ : the value defining the beginning of the constant displacement response range of the spectrum;

$a_{g}:$ the design ground acceleration on Type A ground;

S: the soil factor ( $\mathrm{S}=1.0$ for Type A ground, $\mathrm{S}$ increase as the decrease of ground hardness); $\eta$ : the damping ratio

Figure 2. Seismic response spectrum in EN1998-1 
The value of $T_{B}, T_{C}$ and $T_{D}$ and the soil factor $S$ describing the shape of the elastic response spectrum depend upon the ground type as shown in Table 3:

Table3. Values of the parameters describing the recommended Type 1 and Type 2 elastic response spectra

\begin{tabular}{l|c|c|c|c|c}
\hline $\begin{array}{l}\text { Response } \\
\text { spectra }\end{array}$ & Ground type & $\mathrm{S}$ & $\mathrm{T}_{\mathrm{B}}(\mathrm{s})$ & $\mathrm{T} \mathrm{C}(\mathrm{s})$ & $\mathrm{T}_{\mathrm{D}}(\mathrm{s})$ \\
\hline \multirow{4}{*}{ Type 1 } & $\mathrm{A}$ & 1.0 & 0.15 & 0.4 & 2.0 \\
\cline { 2 - 6 } & $\mathrm{B}$ & 1.2 & 0.15 & 0.5 & 2.0 \\
\cline { 2 - 6 } & $\mathrm{C}$ & 1.15 & 0.20 & 0.6 & 2.0 \\
\cline { 2 - 6 } & $\mathrm{D}$ & 1.35 & 0.20 & 0.8 & 2.0 \\
\cline { 2 - 6 } & $\mathrm{E}$ & 1.4 & 0.15 & 0.5 & 2.0 \\
\hline \multirow{5}{*}{ Type 2 } & $\mathrm{A}$ & 1.0 & 0.05 & 0.25 & 1.2 \\
\cline { 2 - 6 } & $\mathrm{B}$ & 1.3 & 0.05 & 0.25 & 1.2 \\
\cline { 2 - 6 } & $\mathrm{C}$ & 1.5 & 0.10 & 0.25 & 1.2 \\
\cline { 2 - 6 } & $\mathrm{D}$ & 1.8 & 0.10 & 0.30 & 1.2 \\
\cline { 2 - 6 } & $\mathrm{E}$ & 1.6 & 0.05 & 0.25 & 1.2 \\
\hline
\end{tabular}

Response spectrum shapes defined in the GB 50011 Edition 2016 and the EN1998 are similar as showed above, whereas the EN1998 is using the modification coefficients of $T_{B}, T_{C}, T_{D}$ and $S$ to associate the design response spectrum with its ground types and seismic characteristics.

\section{Importance factors}

The GB50068-2001 Unified Standard For Reliability Design Of Building Structures [11] defines the importance factors according to its safety classes, design life and the engineering experience was adaptively applied. The categories were determined as shown in Table 4a and Table $4 \mathrm{~b}$ below:

Table 4a. GB50068-2001 Importance factors for buildings based on safety classes and consequence

\begin{tabular}{c|c|c|c}
\hline safety classes & Consequence & Building Types & Importance factors \\
\hline I & Severe & Important buildings & 1.1 \\
\hline II & Significant & Ordinary buildings & 1.0 \\
\hline III & Minor & Building with minor importance for public safety & 0.9 \\
\hline Other & $/$ & Building with special occupancy & $/$ \\
\hline
\end{tabular}

Table 4b. GB50068-2001 Importance factors for buildings based on design life

\begin{tabular}{c|c|c}
\hline Design life & Description & Importance factors \\
\hline 100 & $\begin{array}{l}\text { Building with particular importance } \\
\text { and monumental buildings }\end{array}$ & 1.1 \\
\hline 50 & Ordinary buildings and structures & 1.0 \\
\hline 25 & Replaceable structure components & Depends on situation \\
\hline 5 & Temporary structure & 0.9 \\
\hline
\end{tabular}

EN1998 classifies buildings into 4 importance classes depending on the consequences of collapse for human life, on their importance for public safety and civil protection in the immediate post-earthquake period, and on the social and economic consequences of collapse [2] as shown in Table 5:
Table5. EN1998-1 Importance factors for buildings

\begin{tabular}{c|l|c}
\hline $\begin{array}{c}\text { Importance } \\
\text { class }\end{array}$ & \multicolumn{1}{|c|}{ Description } & $\begin{array}{c}\text { Importance } \\
\text { factor }\end{array}$ \\
\hline I & Building of minor importance for public saletty, c.g. agricultural buildings, etc. & 0.8 \\
\hline II & Ordinary buildings not belonging in the other categories. & 1.0 \\
\hline III & $\begin{array}{l}\text { Buildings whose seismic resistance is of importance in view of the consequence associated } \\
\text { with a collapse, e.g. schools, assembly hall, cultural institutions etc. }\end{array}$ & 1.2 \\
\hline IV & $\begin{array}{l}\text { Buildings whosc integity during carthquakcs is of vital importance for civil protection, c.g. } \\
\text { hospitals, firc stations, powcr plants, ctc. }\end{array}$ & 1.4 \\
\hline
\end{tabular}

It can be told from Table 4 and Table 5 that the importance factors are approximately divided into 4 categories. The importance factor for class I as defined in EN 1998 (which is 0.8 ) is $11.1 \%$ lower than that for minor importance building defined in GB50068 Edition 2016, and the EN1998-1 has taken $9.1 \%$ and $21.4 \%$ higher value of importance factors in class III and class IV respectively than that in GB50068 Edition 2016.

\section{Comparison in seismic precaution cri- terion and seismic zone classification between the Chinese standard and Eurocode.}

\subsection{Seismic precaution criterion}

The GB50011-2010 (Edition 2016) has introduced three levels of seismic precaution of building as follows: Level 1 requires that the building to remain undamaged and preserve integrity during and after an earthquake incident with $63 \%$ exceedance probability within 50 years (return period equals to 50 years); Level 2 requires the building to maintain repairable during and after an earthquake incident with exceedance probability of $10 \%$ (return period of 475 years); and the Level 3 is the criterion for a building to achieve the requirement for Non-collapse during and after an earthquake incident with exceedance probability of $2 \% \sim 3 \%$ (return period of 2000 years).

EN 1998-1 introduces the performance requirements and compliance criteria as two categories: No-collapse requirement is that the structure shall be capable to withstand the seismic events with a exceedance probability of $10 \%$ within 50 years (return period of 475 years) without local or global collapse; and the Damage limitation requirement indicates that the structure to be capable to withstand the seismic events with a exceedance probability of $10 \%$ within 10 years (return period of 95 years) without the occurrence of damage and associated limitations of use[2].

Following is a graphic comparison between Chinese standard and European standard in seismic precaution levels:

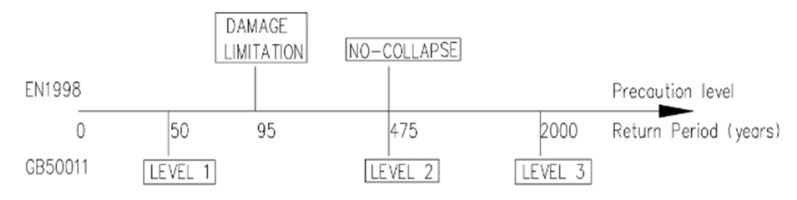

Figure 3. Seismic precaution level comparison between GB50011 Edition 2016 and EN1998

It is straight and clear from the comparison above that Chinese seismic design standard implements three levels of seismic precaution of the building while the European standard has two. Minimum requirement defined in EN 
1998 (damage limitation) is higher than that in GB50011 (Level 1), and the No-Collapse requirement demands a similar precaution conditions to the Level 2 precaution criterion. In addition, GB50011 Edition 2016 provides criterion designed for seismic event with a return period of 2000 years.

In practice, engineers following GB50011 would perform strength check and displacement check for each component of the structure under LEVEL 1 condition. The LEVEL 2 and LEVEL 3 seismic precaution would be achieved by relative detailing measurements for most regular structure, and additional elastic-plastic analysis is required for the weak story, non-regular structure and building with a specified occupation.

Likewise, the EN1998 imposes strength check for components under "No-Collapse" condition and introduces behaviour factor to adjust considering the ductility of different structural types.

\subsection{Seismic precautionary measures}

To consider the hysteretic dissipation capacity and allow the structure to develop stable mechanism under corresponding seismic loading, the EN1998 and GB50011 Edition 2016 provide seismic resistant provision in detailing design and construction measures in building design and component dimension. Depending on the ductile behaviours and energy dissipation capacity under seismic actions, the EN1998 has classified material in two ductility classes DCM (medium ductility) and DCH (high ductility), while the GB50011 divides from class 1 to 4 according to the structure types and height. The differences between the two codes are listed as follows:

1. Axial compressive force ratio. Axial compressive force is a crucial factor for the local ductility and dissipation capacity for column. The EN1998 points out that the value of normalised axial force $\mathrm{V}_{\mathrm{d}}$ shall not exceed 0.65 and 0.55 for DCM and $\mathrm{DCH}$ respectively. By contrast, the GB50011 Edition 2016 adopts 0.65 to 0.9 for class 1 to 4 . As such, looser requirement is desired by the GB50011 that may lead to a smaller cross section and more vulnerable to intensive earthquake.

2. Longitudinal reinforcement ratio. Longitudinal reinforcement contributes to the major seismic performance for beam and column. Therefore, it is indispensable to apply a minimum ratio of longitudinal reinforcement to ensure strength and ductility for the structure. Comparison between the GB50011 and EN1998 is illustrated in Table 6 and Table 7:

Table6. Minimum longitudinal reinforcement ratio of beam

\begin{tabular}{c|c|c|c}
\hline \multicolumn{4}{|c}{ BEAM } \\
\hline Standard & Class & Support end & Midspan \\
\hline \multirow{3}{*}{ GB50011 } & 1 & $\max (0.4 \%, 0.8 \mathrm{ft} / \mathrm{fy})$ & $\max (0.3 \%, 0.65 \mathrm{ft} / \mathrm{fy})$ \\
\cline { 2 - 4 } & 2 & $\max (0.3 \%, 0.65 \mathrm{ft} / \mathrm{fy})$ & $\max (0.2 \%, 0.55 \mathrm{ft} / \mathrm{fy})$ \\
\cline { 2 - 4 } & $3 / 4$ & $\max (0.2 \%, 0.55 \mathrm{ft} / \mathrm{fy})$ & $\max (0.2 \%, 0.45 \mathrm{ft} / \mathrm{fy})$ \\
\hline EN1998 & $\mathrm{DCM} / \mathrm{DCH}$ & \multicolumn{2}{|c}{$0.5(\mathrm{fctm} / \mathrm{fyk})$} \\
\hline
\end{tabular}

Table7. Minimum longitudinal reinforcement ratio of column

\begin{tabular}{c|c|c|c}
\hline \multicolumn{3}{|c}{ COLUMN } \\
\hline Standard & Class & Support end & Midspan \\
\hline \multirow{4}{*}{ GB50011 } & 1 & $1 \%$ & $1.2 \%$ \\
\cline { 2 - 4 } & 2 & $0.8 \%$ & $1 \%$ \\
\cline { 2 - 4 } & 3 & $0.7 \%$ & $0.9 \%$ \\
\cline { 2 - 4 } & 4 & $0.6 \%$ & $0.8 \%$ \\
\hline \multirow{2}{*}{ EN1998 } & DCM/DCH & \multicolumn{2}{|c}{$1 \%$} \\
\hline
\end{tabular}

In a word, the EN1998 demands a slightly higher ratio of longitudinal reinforcement ratio to the GB50011.

3. Critical regions strengthening measures. Critical region is one of the primary parameters in seismic design to prevent brittle failure. Properly enhancement of confinement steel (stirrup) shall be provided in critical regions. Table 8 and Table 9 highlights the comparison in critical regions strengthening measures for beam and column:

Table8. Requirement of hoops for beam end

\begin{tabular}{c|c|c|c|c}
\hline \multicolumn{5}{|c}{ Requirement of stirrups at beam end (unit:mm) } \\
\hline Standard & Class & Critical region length & Spacing of hoops & Minimum dw \\
\hline \multirow{4}{*}{ GB50011 } & 1 & $\operatorname{Max}(2 \mathrm{Hb}, 500)$ & $\operatorname{Min}(\mathrm{Hb} / 4,6 \mathrm{dw}, 100)$ & 10 \\
\cline { 2 - 5 } & 2 & $\operatorname{Max}(1.5 \mathrm{Hb}, 500)$ & $\operatorname{Min}(\mathrm{Hb} / 4,8 \mathrm{dw}, 100)$ & 8 \\
\cline { 2 - 5 } & 3 & $\operatorname{Max}(1.5 \mathrm{Hb}, 500)$ & $\operatorname{Min}(\mathrm{Hb} / 4,8 \mathrm{dw}, 150)$ & 8 \\
\cline { 2 - 5 } & 4 & $\operatorname{Max}(1.5 \mathrm{Hb}, 500)$ & $\operatorname{Min}(\mathrm{Hb} / 4,8 \mathrm{dw}, 150)$ & 6 \\
\hline \multirow{2}{*}{ EN1998 } & $\mathrm{DCM}$ & $\mathrm{Hb}$ & $\operatorname{Min}(\mathrm{Hb} / 4,24 \mathrm{dw}, 225,8 \mathrm{dl})$ & 6 \\
\cline { 2 - 5 } & $\mathrm{DCH}$ & $1.5 \mathrm{Hb}$ & $\operatorname{Min}(\mathrm{Hb} / 4,24 \mathrm{dw}, 175,6 \mathrm{dl})$ & 6 \\
\hline
\end{tabular}

Where:

$\mathrm{Hb}$ : Height of beam

$\mathrm{dw}$ : diameter of hoops

$\mathrm{dl}$ : diameter of longitudinal reinforcement

Table9. Requirement of hoops for column end

\begin{tabular}{|c|c|c|c|c|}
\hline \multicolumn{5}{|c|}{ Requirement of stirrups at column end } \\
\hline Standard & Class & Critical region length & Spacing of hoops & Minimum $d w$ \\
\hline \multirow{4}{*}{ GB50011 } & 1 & \multirow{4}{*}{$\operatorname{Max}(\mathrm{Hc} ; \mathrm{lc} / 6 ; 500)$} & $\operatorname{Min}(6 \mathrm{dw}, 100)$ & 10 \\
\hline & 2 & & $\operatorname{Min}(8 \mathrm{dw}, 100)$ & 8 \\
\hline & 3 & & $\operatorname{Min}(8 \mathrm{dw}, 150)$ & 8 \\
\hline & 4 & & $\operatorname{Min}(8 \mathrm{dw}, 150)$ & 6 \\
\hline \multirow{2}{*}{ EN1998 } & DCM & $\operatorname{Max}(\mathrm{Hc}, \mathrm{lc} / 6,450)$ & $\operatorname{Min}(\mathrm{b} / 2,175,8 \mathrm{~d} 1)$ & 6 \\
\hline & $\mathrm{DCH}$ & $\operatorname{Max}(1.5 \mathrm{Hc}, 1 \mathrm{c} / 6,600)$ & $\operatorname{Min}(\mathrm{b} / 3,125,6 \mathrm{~d} 1)$ & $0.4 \mathrm{dl}^{*}(\mathrm{fydl} / \mathrm{fydw})^{\wedge} 0.5$ \\
\hline
\end{tabular}

Where:

Hc: Height of column

dw: Diameter of hoops

dl: Diameter of longitudinal reinforcement

lc: Clearance length

$\mathrm{b}$ : Minimum dimension of concrete core

The comparison indicates that GB50011 Edition 2016 employs slightly stricter requirements than the EN1998. It is noteworthy that the lowest grade of reinforcement used in the EN1998 has a strength of $\mathrm{f}_{\mathrm{yk}}=400 \mathrm{MPa}$ which is higher than that in GB50011, providing a better shear capacity and it is beneficial to the development of plastic hinge.

\subsection{Seismic zones}

The GB50011 Edition 2016 classifies seismic zone and describes the characters of seismic spectrum according to peak ground acceleration and characteristic period of acceleration response spectrum as specified in GB18306 Seismic Ground Motion Parameters Zonation Map of China. The revised 2016 version of GB50011 had increased the lowest level of seismic intensity class to VI and expanded the range of each classes to abolish the non- 
seismic fortified area defined in the previous version. Detail zonation map can be found in its appendix.

Meanwhile the EN1998-1:2004 3.2.1 uses the peak ground acceleration $\mathrm{agR}_{\mathrm{gR}}$ on Class A site as the single parameter for seismic zones definition. The exceedance possibility for $\mathrm{agR}_{\mathrm{gR}}$ is $10 \%$ in 50 years and the value could be obtained from each national appendix.

Both the GB50011 and EN1998-1 have classified zones based on their seismic risk and consequence. Through numbers of seismologic and geologic researches, index of probability for a certain magnitude of earthquakes in each region is given. Zonation maps are available in the appendix for both standards.

\section{Conclusion}

According to the above studies, the similarities and differences between GB50011 Edition 2016 and EN1998 are concluded in the following, which can be provided as references for structural designers.

1. Ground type classification: GB50011 Edition 2016 dividing the site with index of average shear wave velocity and the overburden thickness of soil, while the EN1998-1 has only adopted the single factor of average shear wave velocity and neglect the soil embedded below 30m; the EN1998-1 requires a deeper calculation depth of average shear wave, and provides more detail classification of ground type than that in GB50011.

2. The impact of ground type on seismic action: Ground type determines both intensity and the value of characteristic period of the response spectrum in EN19981, while in the GB50011 it has no impact on the characteristic period of the response spectrum.

3. Response spectrum: The shape of a design response spectrum given by both standards is similar, while the EN1998-1 determines the value of $\mathrm{T}_{\mathrm{B}}, \mathrm{T}_{\mathrm{C}}, \mathrm{T}_{\mathrm{D}}, \mathrm{S}$ by ground type and the seismic characters.

4. Importance factor: The importance factor in the GB50011 and EN1998-1 is roughly divided into four classes, where the importance factor for class I as defined in EN 1998 (which is 0.8 ) is $11.1 \%$ lower than that for minor importance building defined in GB50068, and the EN1998 has taken $9.1 \%$ and $21.4 \%$ higher value of importance factors in class III and class IV respectively than that in GB50068.

5. Seismic precautionary criterion: The minimum requirement defined in EN 1998 (damage limitation) is higher than that in GB50011 (Level 1), and the "NoCollapse requirement" has a similar exceedance probability and return-period while the GB50011 demands a slightly higher fortification requirement for Level 2. In addition, the GB50011 provides criterion designed for seismic event with return period of 2000 years.

6. Seismic precautionary measures: the GB50011 has imposed slightly stricter constructional measures to ensure ductility and strength of components in terms of hoops diameter and spacing. On the contrary the EN1998 is suggesting an increased area of reinforcement and higher grade of steel which provides better mechanical performance.
7. Seismic Zone: Both the GB50011 and EN1998 have classified zones based on their seismic risk and consequence. With numbers of seismologic and geologic researches both standards signalled the index of probability for a certain magnitude of earthquakes in each region. Zonation maps are available in the appendix for both standards.

However, this paper is only general comparison between the two codes, it is necessary to add more case studies to conclude differences for the future research, and provide more detailed reference how to apply the EN 1998 in the structural design.

\section{Reference}

1. CHINA ARCHITECTURE \& BUILDING PRESS, GB50011-2010: Code For Seismic Design of Buildings. (2016).

2. BSI, BS EN 1998-1:2004 Part 1: General rules, seismic actions and rules for buildings. (2004)

3. BSI, BS EN 1998-2:2005 Part 2: Bridges. (2005)

4. BSI, BS EN 1998-3:2005 Part 3: Assessment and retrofitting of buildings. (2005)

5. BSI, BS EN 1998-4:2006 Part 4: Silos, tanks and pipelines. (2006)

6. BSI, BS EN 1998-5:2004 Part 5: Foundations, retaining structures and geotechnical aspects. (2004)

7. BSI, BS EN 1998-6 Part 6:2005: Towers, masts and chimneys. (2005)

8. Y. Song. The Comparison of seismic design code of buildings between China and Europe. (2004)

9. X. Hu. Comparison of Chinese codes and Europe codes about Seismic Design Provisions (2005)

10. L. Chen, C. Chen, S. Wang, Comparative study of seismic design codes of China and Europe. (Engineering Science Journal of Wuhan University, 46: Page 129-134, 2013),

11. CHINA ARCHITECTURE \& BUILDING PRESS, GB50068-2001: Unified Standard for Reliability Design of Building Structures (2001)

12. STANDARDS PRESS OF CHINA, GB18306-2015: Zoning map of ground motion parameters in China (2015) 